\begin{tabular}{|c|c|}
\hline Title & Turn-to-Turn Contact Resistance Measurement of No-Insulation REBCO Pancake Coil: External Field Dependence \\
\hline Author(s) & $\begin{array}{l}\text { Noguchi, So; Mori, Shunpei; Mato, Takanobu; Tatsuta, T akahiro; Nishikawa, Daisuke; Miyamoto, Kohei; Inoue, Ryota; } \\
\text { Ueda, Hiroshi; Kim, SeokBeom }\end{array}$ \\
\hline Citation & $\begin{array}{l}\text { IEEE transactions on applied superconductivity, 31(5), } 4602105 \\
\text { https://doi.org/10.1109// A SC.2021.3070232 }\end{array}$ \\
\hline Issue Date & 2021-08 \\
\hline Doc URL & http:/hdl.handle.net/2115/82850 \\
\hline Rights & $\begin{array}{l}\text { (c) } 2021 \text { IEEE. Personal use of this material is permitted. Permission from IEEE must be obtained for all other uses, in } \\
\text { any current or future media, including reprinting/republishing this material for advertising or promotional purposes, } \\
\text { creating new collective works, for resale or redistribution to servers or lists, or reuse of any copy righted component of } \\
\text { this work in other works. }\end{array}$ \\
\hline Tyре & article (author version) \\
\hline File Information & RcMeasurement-ver3-Kim.pdf \\
\hline
\end{tabular}

Instructions for use 


\title{
Turn-to-turn Contact Resistance Measurement of No- Insulation REBCO Pancake Coil: External Field Dependence
}

\author{
So Noguchi, Shunpei Mori, Takanobu Mato, Takahiro Tatsuta, Daisuke Nishikawa, Kohei Miyamoto, Ryota Inoue, \\ Hiroshi Ueda, and SeokBeom Kim
}

\begin{abstract}
The characteristics of no-insulation hightemperature superconducting (HTS) manet is dominated by the magnitude of the turn-to-turn contact resistance. A few techniques have been proposed to increase the turn-to-turn contact resistance. The relation between the turn-to-turn contact resistance and the magnet stability has also been investigated in simulations. Although the turn-to-turn contact resistance measurement was only the sudden-discharging method before, we proposed a lowfrequency-AC current (LFAC) method. Using our proposed method, it is possible to measure the turn-to-turn contact resistance under various conditions. In a previous paper, we measured it when charging DC current to a single pancake coil. In this paper, the turn-to-turn contact resistance was measured by the LFAC method when an external field of 1-3 $T$ was applied to a single pancake coil. The coil strain was also measured, and the relation of the turn-to-turn contact resistance and the coil strain was also discussed.
\end{abstract}

Index Terms-No-insulation winding technique, REBCO pancake coil, turn-to-turn contact resistance measurement.

\section{INTRODUCTION}

$\mathrm{T}$ HE stability of rare-earth barium copper oxide (REBCO) pancake coils is drastically enhanced with a no-insulation (NI) winding technique [1]. Following the NI winding technique, some methods of increasing the REBCO magnet stability have been proposed; a metal insulation technique [2], [3], a metal cladding [4], the use of thermal grease [5], a smart switching by metal-insulator transition (MIT) [6], and a coating with electrically conductive epoxy resin [7]. A key of these techniques is the increase in the contact resistance. The high contact resistance yields a short charging delay; however, too high contact resistance loses the stability. The influence of the turn-to-turn contact resistance on the thermal stability of REBCO pancake coils were discussed in [8], [9].

Although the turn-to-turn contact resistance is an important factor, its dependence of magnetic field, stress, or temperature is not clear. Because, commonly, the turn-to-turn contact resistance is measured by means of a sudden-discharging test. That is, the operating current of NI REBCO pancake coils suddenly cuts off, and the time constant of the field decay is

This work was supported by the JSPS KAKENHI under Grant No. 20H02125. (Corresponding author: So Noguchi.)

S. Noguchi, S. Mori, and T. Mato are with the Graduate School of Information Science and Technology, Hokkaido University, Sapporo 060-0814, Japan. (e-mail: noguchi@ssi.ist.hokudai.ac.jp). measured to estimate the turn-to-turn contact resistance. The sudden-discharging test is impossible to measure the contact resistance under various conditions.

In our previous paper [10], a low-frequency-AC current (LFAC) method was proposed to measure the contact resistance. On this method, applying a low-frequency-AC current to an NI pancake coil, the AC impedance, which corresponds to the contact resistance, is measured. The validity of the proposed method was confirmed [10].

In this paper, the AC impedances of NI REBCO pancake coil are shown, when an external field of $1-3 \mathrm{~T}$ is applied to an NI REBCO single pancake at DC current operation. The coil strain was measured with strain gages. The dependence of the contact resistance on the coil strain is also discussed.

\section{LFAC EXPERIMENTS}

\section{A. LFAC method}

We have previously proposed a low-frequency-AC current method to measure the turn-to-turn contact resistance of NI REBCO pancake coil [10], [11]. In the proposed LFAC method, by applying a low-frequency AC current to an NI REBCO pancake coil or superimposing on a DC transport current, the coil impedance is measured. When the following condition is held, the coil impedance $Z$ is the turn-to-turn contact resistance $R_{\mathrm{ct}}\left(Z=R_{\mathrm{ct}}\right)[10]$ :

$$
\left|\frac{R_{\mathrm{ct}}}{j \omega L}\right| \ll 1
$$

where $j, \omega$, and $L$ are the imaginary unit, the AC current angular frequency, and the coil inductance, respectively. The $\mathrm{AC}$ current frequency of $1 \mathrm{~Hz}$ to $50 \mathrm{~Hz}$ is preferred to a small single pancake coil with small inductance [10], [11].

\section{B. Test Coil and Experiment Conditions}

An NI REBCO pancake coil with 20 turns was used for LFAC contact resistance measurement (as illustrated in Fig. 1). Table I lists the properties of REBCO tape and strain gauge and the specifications of test NI REBCO coil. The coil was wound with a tension of $1 \mathrm{~kg}$. Fig. 2 shows the coil photos at winding start and end.

T. Tatusta, D. Nishikawa, K. Miyamoto, R. Inoue, H. Ueda, and S. Kim are with the Graduate School of Natural Science and Technology, Okayama University, Okayama 700-8530, Japan. 


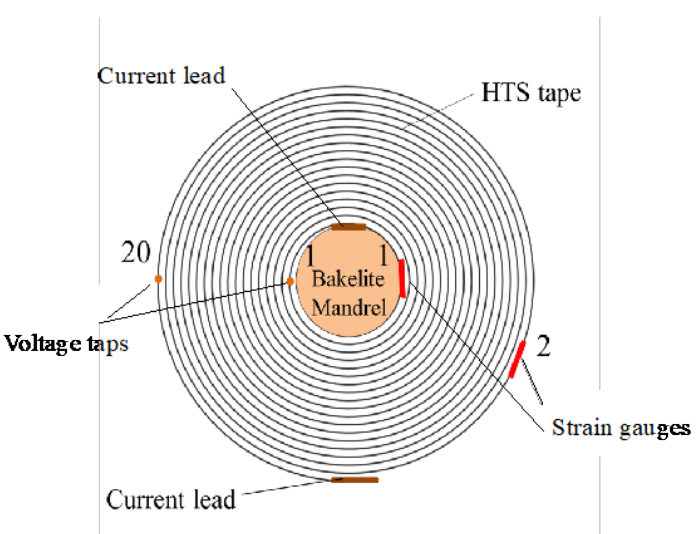

(a) Top view

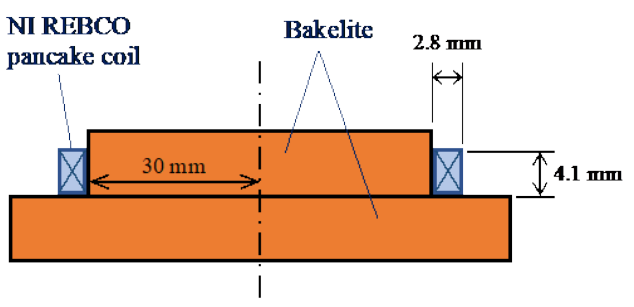

(b) Side view

Fig. 1. Illustration of test NI REBCO coil with 20 turns. Two strain gauge are attached to innermost and outermost turns.

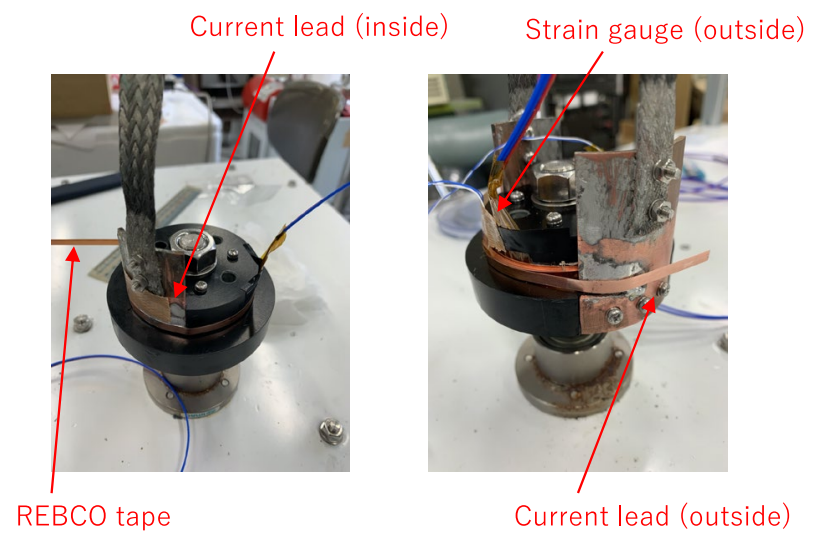

Fig. 2. Photos of start winding (left) and end winding (right).

The LFAC test was conduction cooled by immersion in liquid nitrogen. The external fields of 1,2 , and $3 \mathrm{~T}$ were applied to the test coil. The RT bore of superconducting magnet is 100 $\mathrm{mm}$, and the maximum field is $10 \mathrm{~T}$. The operating current increased up to $\pm 50 \mathrm{~A}(1 \mathrm{~T}), \pm 30 \mathrm{~A}(2 \mathrm{~T})$, and $\pm 20 \mathrm{~A}(3 \mathrm{~T})$. Here, when a negative current was carried, an inward electromagnetic force acted on the test coil. Superimposing a $10-\mathrm{Hz}$ AC current of $10 \mathrm{~A}$ (peak), the turn-to-turn contact resistances were measured every $10 \mathrm{~A}$. The strains on the inner and outer surface of the test coil were also measured.

\section{LFAC MEASUREMENT RESULTS}

\section{A. Measurements of Strain and Turn-to-Turn Contact Resistance}

Fig. 3 plots the transition of the measured strain and turn-toturn contact resistance $R_{\mathrm{ct}}$ in the case of 1-T external field. The
TABLE I

\begin{tabular}{lc} 
REBCO TAPE, STRAIN GAUGE, AND PANCAKE COIL PROPERTIES \\
\hline REBCO tape width $(\mathrm{mm})$ & 4.1 \\
REBCO tape thickness $(\mu \mathrm{m})$ & 144 \\
REBCO layer thickness $(\mu \mathrm{m})$ & 1 \\
Substrate thickness $(\mu \mathrm{m})$ & 100 \\
Critical current @ $77 \mathrm{~K}$, s.f. $(\mathrm{A})$ & 229 \\
\hline \hline Strain gauge width $(\mathrm{mm})$ & 1 \\
Strain gauge length $(\mathrm{mm})$ & 0.2 \\
Strain gauge thickness $(\mu \mathrm{m})$ & 50 \\
Strain gauge resistance $(\mu \Omega)$ & 120 \\
\hline \hline Number of turns & 20 \\
Coil i.d.; o.d. $(\mathrm{mm})$ & $60 ; 65.76$ \\
Coil height $(\mathrm{mm})$ & 4.1 \\
Calculated inductance $(\mu \mathrm{H})$ & 48.8 \\
Operating current $(\mathrm{A})$ & $10-50$ \\
External field $(\mathrm{T})$ & $1,2,3$ \\
\hline
\end{tabular}

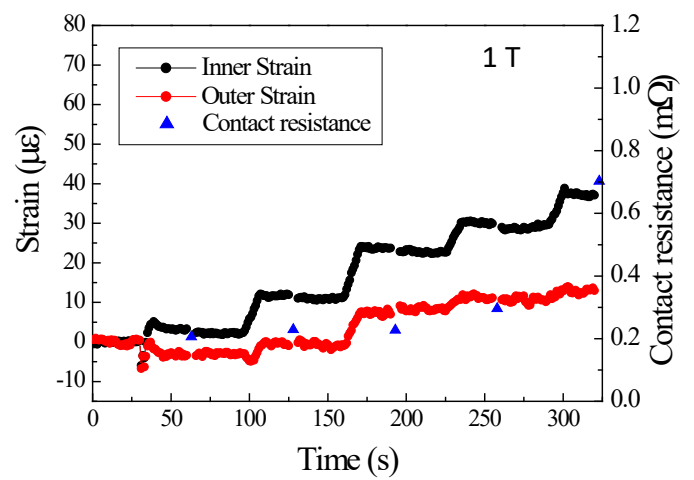

(a)

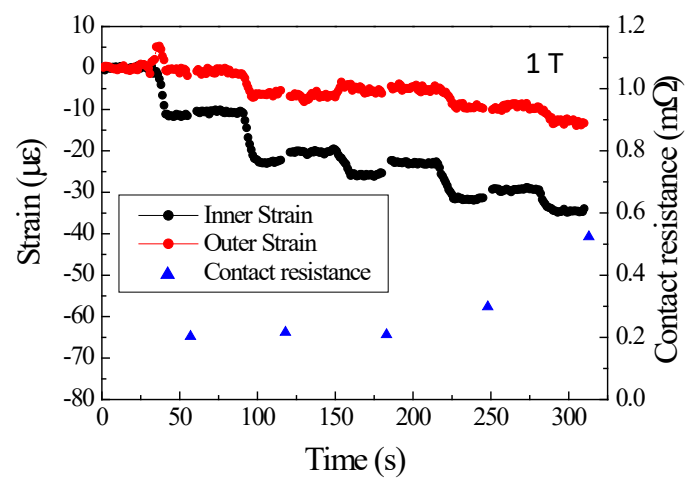

(b)

Fig. 3. Inner and outer strains and the turn-to-turn contact resistance $R_{\mathrm{ct}}$ while increasing DC transport current in the cases of (a) outward and (b) inward force, applying 1-T external field. The DC current varied from 0 to $50 \mathrm{~A}$, and $R_{\mathrm{ct}}$ was measured every $10-\mathrm{A}$ DC current.

error of strain gauge against the measured value of $10 \mu \varepsilon$ is 0.3 $\mu \varepsilon$. The strain increased/decreased with current. When superimposing the $\mathrm{AC}$ current every $10 \mathrm{~A}$ in order to measure the turn-to-turn contact resistance $R_{\mathrm{ct}}$, the amount of the strain decreased. The vibrating electromagnetic force by the $\mathrm{AC}$ current would slightly release the winding tension. Or, the screening current affect the measured strain. We will find out the reason by simulation in the future.

The magnitude of strain on the inner side of the coil is larger than the outer side in the both cases of the inward and outward forces. When the mandrel and the inner side of the coil are mechanically contacted, the radial stress in the coil with the 


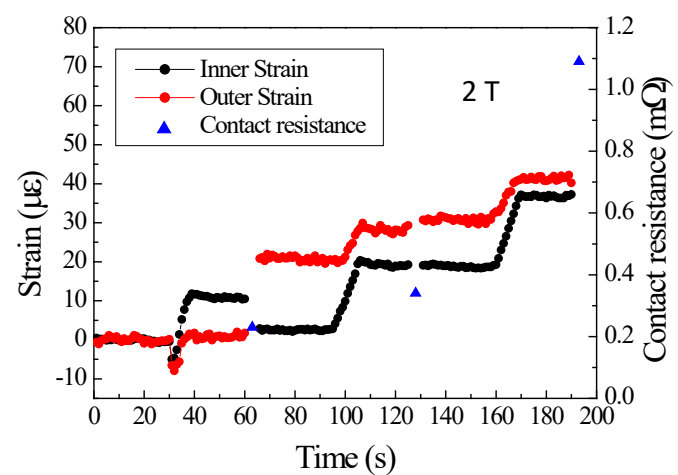

(a)

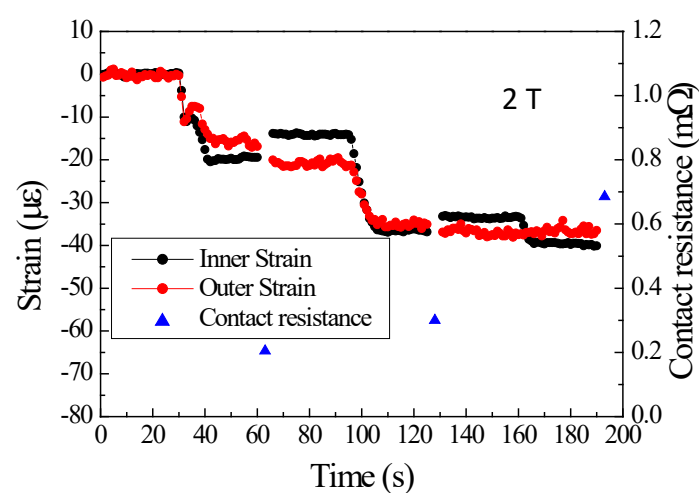

(b)

Fig. 4. Inner and outer strains and the turn-to-turn contact resistance $R_{\mathrm{ct}}$ while increasing DC transport current in the cases of (a) outward and (b) inward force, applying 2-T external field. The DC current varied from 0 to $30 \mathrm{~A}$, and $R_{\mathrm{ct}}$ was measured every $10-\mathrm{A}$ DC current.

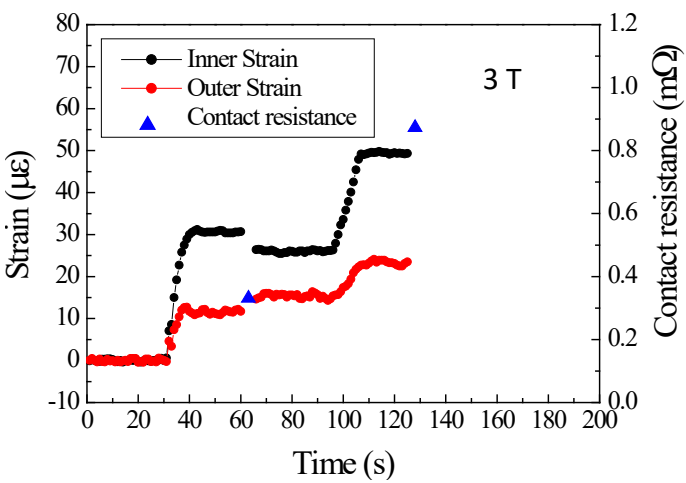

(a)

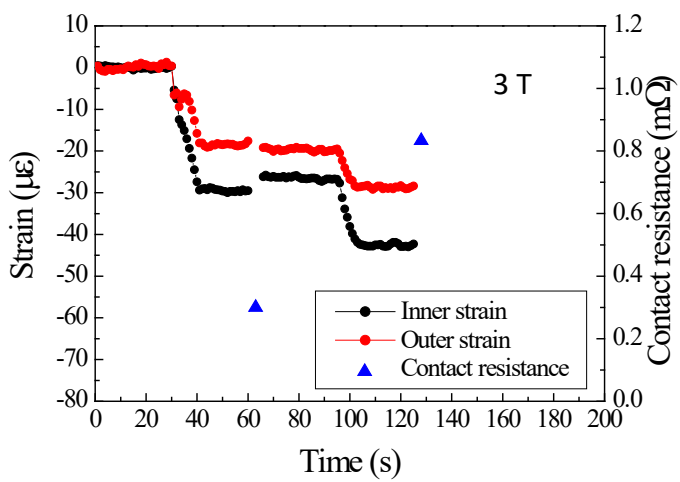

(b)

Fig. 5. Inner and outer strains and the turn-to-turn contact resistance $R_{\mathrm{ct}}$ while increasing DC transport current in the cases of (a) outward and (b) inward force, applying 3-T external field. The DC current varied from 0 to $20 \mathrm{~A}$, and $R_{\mathrm{ct}}$ was measured every $10-\mathrm{A}$ DC current.

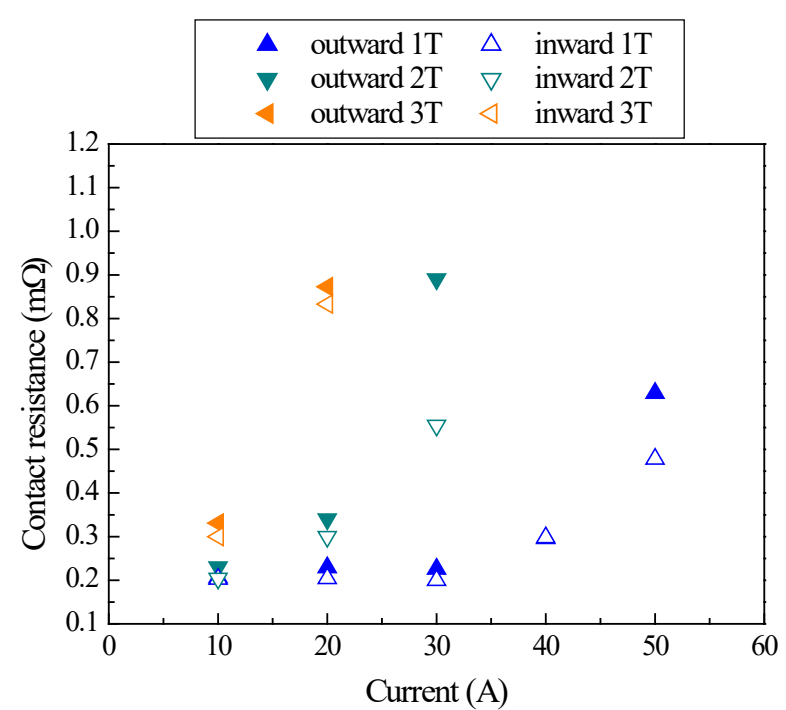

Fig. 6. Measured the turn-to-turn contact resistances of the inward and outward forces vs. the magnitude of DC current.

inward force is much larger than the outward force. On the other hand, the hoop stress on the inner side of the coil is larger than the outside in the both cases. Therefore, it is considered that the strain gauge installed in the coil accurately measures the hoop stress of the coil due to the electromagnetic force. The measured contact resistance is $0.2 \mathrm{~m} \Omega$ up to a DC current of $30 \mathrm{~A}$ and increases above $30 \mathrm{~A}$ as shown in Fig.3 (a) and (b).

Meanwhile, we cannot find a reason why the turn-to-turn contact resistance $R_{\mathrm{ct}}$ increases with DC transport current in the case of the outward force [Fig. 3(a)].

Next, the strain and turn-to-turn contact resistance transitions at external fields of 2 and $3 \mathrm{~T}$ are shown in Figs. 4 and 5, respectively. The same contact resistance increase tendency as Fig. 3 can be observed. In addition, the inner strain is larger than the outer strain only in the case of outward 2-T external field. The reason is not clear now. Meanwhile, the inner and outer strains are equalized applying the $\mathrm{AC}$ current. The REBCO tape slightly moves in the azimuthal direction by a vibrating force larger than the friction between REBCO tapes.

\section{B. Discussion}

Fig. 6 plots the turn-to-turn contact resistance $R_{\mathrm{ct}}$ and resistivities $\rho_{\mathrm{ct}}$ vs. the magnitude of the DC current. The obtained contact resistivity is larger than $70 \mu \Omega \cdot \mathrm{cm}^{2}$ measured in [12]. The contact resistance increases with the current in all the cases of 1,2, and 3-T external field. The difference between the force direction cannot be seen, except for $30 \mathrm{~A}$ at $2 \mathrm{~T}$. Since there is no strong correlation of the $R_{\mathrm{ct}}$ contact resistance to the DC current, it can be inferred that there is less effect of AC loss.

Fig. 7 shows the calculated electromagnetic force on the inner and outer surface of the test coil and the turn-to-turn contact resistance vs. the DC operating current. The electromagnetic force increases/decreases with the DC current, and the difference of the electromagnetic force on the inner and outer surface of coil widens with the increase in the DC current. Next, the turn-to-turn contact resistance is plotted to the average of electromagnetic force in Fig. 8. The turn-to-turn contact 


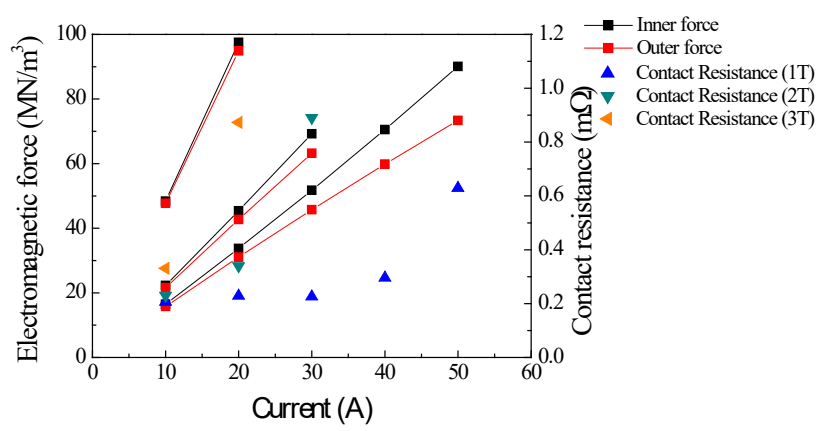

(a)

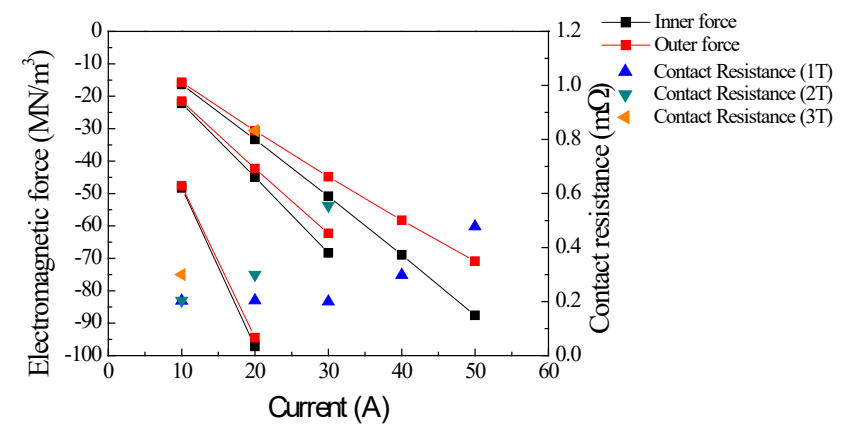

(b)

Fig. 7. Inner and outer strains and the turn-to-turn contact resistance $R_{\mathrm{ct}}$ while increasing DC transport current in the cases of (a) outward and (b) inward force, applying 2-T external field. The DC current varied from 0 to $30 \mathrm{~A}$, and $R_{\mathrm{ct}}$ was measured every $10-\mathrm{A}$ DC current.

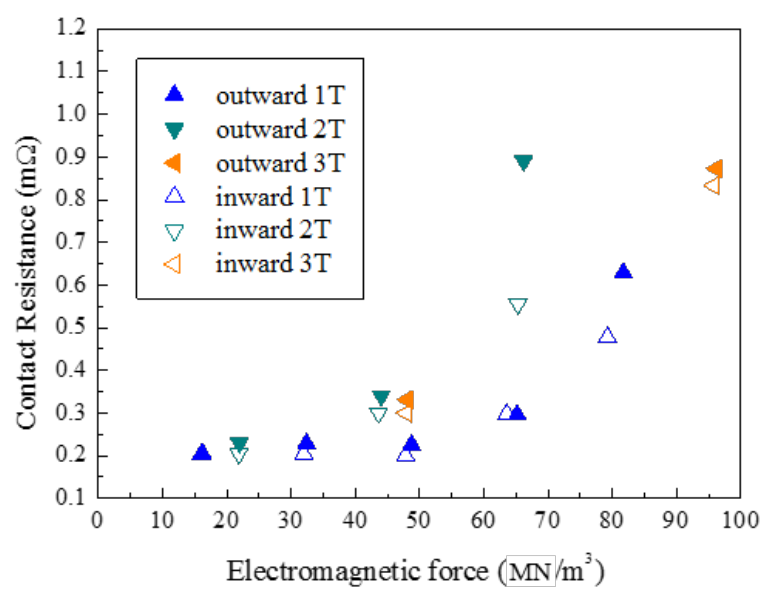

Fig. 8. Relation of turn-to-turn contact resistance $R_{\text {ct }}$ and average electromagnetic force.

resistance correlates with the magnitude of electromagnetic force, regardless of its direction. At this moment, it is impossible to explain the mechanism of turn-to-turn contact resistance increasing with the electromagnetic force. It is necessary to simulate the stress phenomenon in order to clarify the relation.

\section{Voltage Waveform}

Fig. 9 shows the voltage waveform in the case of 30-A DC current under 2-T external field (outward force). The peak-topeak voltage is approximately $21 \mathrm{mV}$, where the upper and lower peaks are 6 and $-15 \mathrm{mV}$, respectively. The center shifts to $-4.5 \mathrm{mV}$.

When a simple equivalent circuit of NI REBCO single

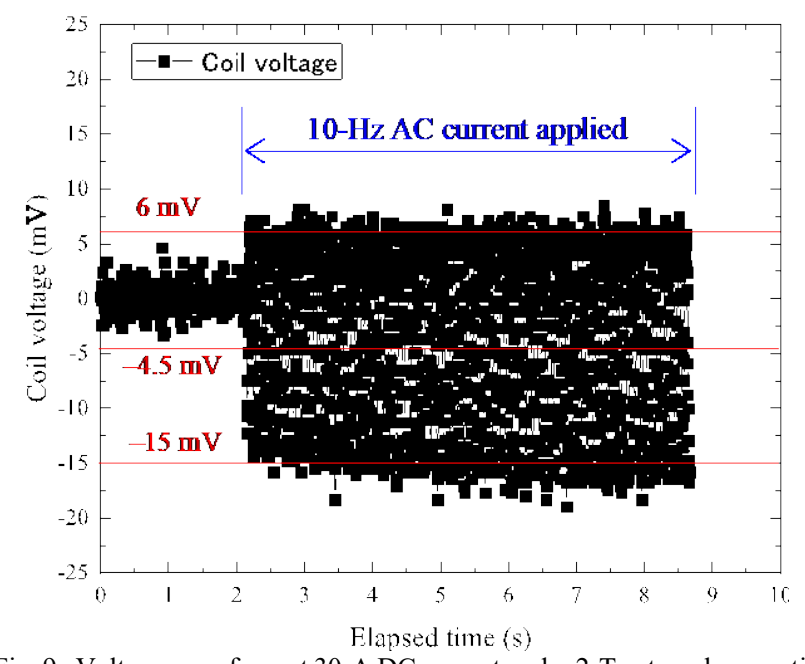

Fig. 9. Voltage waveform at 30-A DC current under 2-T external magnetic field, superimposing $10-\mathrm{Hz} 10-\mathrm{A}$ (peak) AC to DC current.

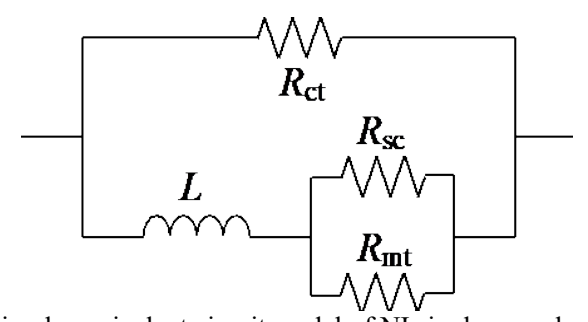

Fig. 10. Simple equivalent circuit model of NI single pancake coil. $R_{\mathrm{ct}}, L$, $R_{\mathrm{sc}}$, and $R_{\mathrm{mt}}$ are the turn-to-turn contact resistance, the coil inductance, the REBCO resistance, and the matrix resistance, respectively.

pancake, as shown in Fig. 10 [1], [12] is adopted, the coil impedance $Z$ is as follows:

$$
Z=\frac{j \omega L R_{\mathrm{ct}}}{R_{\mathrm{ct}}+j \omega L}
$$

where $j, \omega, L$, and $R_{\mathrm{ct}}$ are the imaginary unit, the angular frequency, the coil inductance, and the turn-to-turn contact resistance, respectively. Here, it is assumed that the REBCO layer resistance is zero $\left(R_{\mathrm{sc}}=0\right)$. According to (2), the coil impedance is $Z=0.965 \times 10^{-3}+j 5.45 \times 10^{-6}$. The real part is much larger than imaginary, meeting the condition of (1). Hence, the coil voltage must shift to positive not negative. In the near future, it is necessary to simulate the voltage using a more complicated model, such as the partial element equivalent circuit (PEEC) method [13].

\section{CONCLUSION}

We measured the turn-to-turn contact resistance of NI REBCO single pancake with DC transport current under external fields of 1,2 , and $3 \mathrm{~T}$, using a low-frequency $\mathrm{AC}$ current (LFAC) method. The turn-to-turn contact resistance correlates the electromagnetic force; however, not the inward/outward force directions. An unexplainable voltage shift was also observed.

In the future, the voltage/current phenomenon will be clarified using a more complicated model, such as a partial element equivalent circuit (PEEC) model. 


\section{REFERENCES}

[1] S. Hahn, D. K. Park, J. Bascuñán, and Y. Iwasa, "HTS pancake coils without turn-to-turn insulation," IEEE Trans. Appl. Supercond., vol. 21, no. 3, pp. 1592-1595, Jun. 2011.

[2] T. Lécrevisse, and Y. Iwasa, "A (RE)BCO pancake winding with metalas-insulation," IEEE Trans. Appl. Supercond., vol. 26, no. 3, Apr. 2016, Art. no. 4700405.

[3] S. B. Kim, T. Kaneko, H. Kajikawa, J. H. Joo, J. Jo, Y. Han, and H. Jeong, "The transient stability of HTS coils with and without the insulation and with the insulation being replaced by brass tape," IEEE Trans. Appl. Supercond., vol. 23, no. 3, Jun. 2013, Art. no. 7100204.

[4] J. Kim, S. Yoon, K. Cheon, K. H. Shin, S. Hahn, D. L. Kim, S. Lee, H. Lee, and S. Moon, "Effect of resistive metal cladding of HTS tape on the characteristic of no-insulation coil," IEEE Trans. Appl. Supercond., vol. 26, no. 4, Mar. 2016, Art. no. 4601906.

[5] S. Kim, Y. H. Choi, D. G. Yang, Y. Kim, and H. Lee, "Charge-discharge and thermal-electrical characteristics of $\mathrm{GdBCO}$ coils wound with various types of grease as an insulation material, IEEE Trans. Appl. Supercond., vol. 26, no. 4, Jun. 2016, Art. no. 4601004.

[6] S. Kim, J. Hur, S. Kim, S. Kim, R. Ko, D. Ha, H. M. Kim, J. Joo, and Y. Jo, "Improvement in stability and operating characteristics of HTS coil using MIT material," IEEE Trans. Appl. Supercond., vol. 27, no. 4, Jun. 2017, Art. no. 4601704.

[7] H. Miyazaki, S. Iwai, T. Uto, T. Kusano, Y. Otani, K. Koyanagi, and S. Nomura, "Over-current test of REBCO pancake coils impregnated with electrically conductive epoxy resin under conduction-cooled conditions," IEEE Trans. Appl. Supercond., vol. 29, no. 5, Apr. 2019, Art. no. 4602805.

[8] K. Katsumata, T. Wang, A. Ishiyama, S. Noguchi, K. Monma, S. Nagaya, and T. Watanabe, "Influence of the turn-to-turn contact electrical resistance on the thermal stability in meter-class no-insulation REBCO pancake coils during a local normal-state transition," IEEE Trans. Appl. Supercond., vol. 27, no. 4, Jun. 2017, Art. no. 4602005.

[9] S. Noguchi, S. Hahn, A. Ishiyama, and Y. Iwasa, "A simple protection evaluation method for no-insulation REBCO pancake coils during local normal-state transition," Supercond. Sci. Trchnol., vol. 32, no. 4, Apr. 2019, Art. no. 045001.

[10] S. Noguchi, R. Miyao, H. Okusa, T. Tatsuta, H. Ueda, and S. Kim, "Turnto-turn contact resistance measurement of no-insulation REBCO pancake coila," IEEE Trans. Appl. Supercond., vol. 29, no. 5, Aug. 2019, Art. no. 4601605.

[11] S. Noguchi, T. Tatsuta, D. Nishikawa, H. Ueda, and S. Kim, “Turn-toturn contact resistance measurement of no-insulation REBCO pancake coil at DC current operation," IEEE Trans. Appl. Supercond., vol. 30, no. 4, Jun. 2020, Art. no. 9000305.

[12] X. Wang, S. Hahn, Y. Kim, J. Bascuñán, J. Voccio, H. Lee, and Y. Iwasa, "Turn-to-turn contact characteristics for an equivalent circuit model of noinsulation REBCO pancake coil," Supercond. Sci. Technol., vol. 26, no. 3, Mar. 2013, Art. no. 035012.

[13] T. Wang, S. Noguchi, X. Wang, I. Arakawa, K. Minami, K. Monma, A. Ishiyama, S. Hahn, and Y. Iwasa, "Analyses of Transient behaviors of noinsulation REBCO pancake coils during sudden discharging and overcurrent," IEEE Trans. Appl. Supercond., vol. 25, no. 3, Jun. 2015, Art. no. 4603409 . 